\title{
Predictors of insufficient peak amikacin concentration in critically ill patients on extracorporeal membrane oxygenation
}

\author{
Cyril Touchard', Alexandra Aubry², Philippine Eloy ${ }^{3}$, Nicolas Bréchot', Guillaume Lebreton ${ }^{4}$, \\ Guillaume Franchineau', Sebastien Besset ${ }^{1}$, Guillaume Hékimian'1, Ania Nieszkowska', Pascal Leprince ${ }^{4}$, \\ Charles-Edouard Luyt ${ }^{1}$, Alain Combes $^{1}$ and Matthieu Schmidt ${ }^{1 *}$
}

\begin{abstract}
Background: Amikacin infusion requires targeting a peak serum concentration $\left(C_{\max }\right) 8-10$ times the minimal inhibitory concentration, corresponding to a $C_{\max }$ of $60-80 \mathrm{mg} / \mathrm{L}$ for the least susceptible bacteria to theoretically prevent therapeutic failure. Because drug pharmacokinetics on extracorporeal membrane oxygenation (ECMO) are challenging, we undertook this study to assess the frequency of insufficient amikacin $C_{\max }$ in critically ill patients on ECMO and to identify relative risk factors.

Methods: This was a prospective, observational, monocentric study in a university hospital. Patients on ECMO who received an amikacin loading dose for suspected Gram-negative infections were included. The amikacin loading dose of $25 \mathrm{mg} / \mathrm{kg}$ total body weight was administered intravenously and $C_{\max }$ was measured $30 \mathrm{~min}$ after the end of the infusion. Independent predicators of $C_{\max }<60 \mathrm{mg} / \mathrm{L}$ after the first amikacin infusion were identified with mixed-model multivariable analyses. Various dosing simulations were performed to assess the probability of reaching $60 \mathrm{mg} / \mathrm{L}<\mathrm{C}_{\max }<$ $80 \mathrm{mg} / \mathrm{L}$.

Results: A total of 106 patients on venoarterial ECMO (VA-ECMO) (68\%) or venovenous-ECMO (32\%) were included. At inclusion, their median (1st; 3rd quartile) Sequential Organ-Failure Assessment score was 15 (12; 18) and 54 patients (51\%) were on renal replacement therapy. Overall ICU mortality was $54 \%$. $C_{\max }$ was $<60 \mathrm{mg} / \mathrm{L}$ in 41 patients (39\%). Independent risk factors for amikacin under-dosing were body mass index $(\mathrm{BMI})<22 \mathrm{~kg} / \mathrm{m}^{2}$ and a positive $24-\mathrm{h}$ fluid balance. Using dosing simulation, increasing the amikacin dosing regimen to $30 \mathrm{mg} / \mathrm{kg}$ and $35 \mathrm{mg} / \mathrm{kg}$ of body weight when the 24-h fluid balance is positive and the BMl is $\geq 22 \mathrm{~kg} / \mathrm{m}^{2}$ or $<22 \mathrm{~kg} / \mathrm{m}^{2}$ (Table 3), respectively, would have potentially led to the therapeutic target being reached in $42 \%$ of patients while reducing under-dosing to $23 \%$ of patients.

Conclusions: ECMO-treated patients were under-dosed for amikacin in one third of cases. Increasing the dose to $35 \mathrm{mg} /$ $\mathrm{kg}$ of body weight in low-BMl patients and those with positive 24-h fluid balance on ECMO to reach adequate targeted concentrations should be investigated.
\end{abstract}

Keywords: Amikacin, Pharmacokinetics, Acute respiratory distress syndrome, Cardiac failure, Shock, Volume of distribution

\footnotetext{
* Correspondence: matthieuschmidt@yahoo.fr; matthieu.schmidt@aphp.fr

${ }^{1}$ Medical Intensive Care Unit, iCAN, Institute of Cardiometabolism and

Nutrition, Hôpital de la Pitié-Salpêtrière, Assistance Publique-Hôpitaux de

Paris, Sorbonne University, Paris 6, 47, bd de l'Hôpital, 75651 Paris Cedex 13,

France

Full list of author information is available at the end of the article
}

(c) The Author(s). 2018 Open Access This article is distributed under the terms of the Creative Commons Attribution 4.0 International License (http://creativecommons.org/licenses/by/4.0/), which permits unrestricted use, distribution, and reproduction in any medium, provided you give appropriate credit to the original author(s) and the source, provide a link to the Creative Commons license, and indicate if changes were made. The Creative Commons Public Domain Dedication waiver (http://creativecommons.org/publicdomain/zero/1.0/) applies to the data made available in this article, unless otherwise stated. 


\section{Background}

Over the last decade, a growing number of patients have benefited from extracorporeal membrane oxygenation (ECMO) as rescue therapy for patients suffering from severe acute respiratory distress syndrome (ARDS) or refractory cardiogenic shock [1]. More than half of them will require antibiotic therapy during their ECMO run to treat a primary infection or secondary acquired infection [2]. Because little is known about the impact of ECMO on antibiotic pharmacokinetics (PK), antibiotic administration on ECMO remains a challenge. Although suboptimal antibiotic dosing in this complex group of patients may have fatal consequences, available data are actually limited to animal [3], simulated ex-vivo [4], or small retrospective human studies [5]. Sequestration in the circuit, increased volumes of distribution ( $\mathrm{Vd})$, and decreased drug clearance have been implicated to explain antibiotic-PK modifications in that context [6]. Moreover, the underlying disease in these extremely severely ill patients may also be key. Empirical combination antibiotic therapy, aimed at covering Gram-negative bacilli, usually combines a $\beta$-lactam and an aminoglycoside [7]. Considering its good bactericidal activity against Pseudomonas aeruginosa and its low resistance rate observed with other Gram-negative bacilli, amikacin is frequently used in that context [8]. Its antibacterial effect is determined by the ratio of peak serum concentration $\left(C_{\max }\right)$ to the targeted pathogen's minimal inhibitory concentration (MIC), with optimal antibacterial activity obtained with a $\mathrm{C}_{\max } / \mathrm{MIC}$ ratio of $8-10$. Consequently, the amikacin $C_{\max }$ range should be 64$80 \mathrm{mg} / \mathrm{L}$ [9], while the most recent French guidelines recommended $\mathrm{C}_{\max }>60 \mathrm{mg} / \mathrm{L}$ [10]. Despite administering an amikacin dose of $25 \mathrm{mg} / \mathrm{kg}$ total body weight (TBW), only $67-72 \%$ of intensive care unit (ICU) patients have been found to achieve that objective [11, 12]. In this setting, further PK changes in ECMO-treated patients would be anticipated. Therefore, this open-label, monocentric, prospective study was designed to determine the frequency and identify factors predictive of insufficient amikacin $C_{\max }$ in critically ill patients, and to analyze the probability of attaining the established PK target (i.e. greater than $60 \mathrm{mg} / \mathrm{L}$ but below $80 \mathrm{mg} / \mathrm{L}$ ).

\section{Methods}

\section{Setting}

This prospective observational study was conducted in a 26-bed medical-surgical ICU at a university hospital. Its protocol was in accordance with the ethical standards of our hospital's Institutional Review Board (Committee for the Protection of Human Subjects). In accordance with French law, informed consent was not obtained for demographic, physiological and hospital-outcome data analyses because this observational study did not modify existing diagnostic or therapeutic strategies. However, patients and/or relatives were informed about the anonymous data collection and that they could decline inclusion. This database was registered at the Commission Nationale l'Informatique et des Libertés (CNIL, registration number 1950673).

\section{Study design and patients}

We prospectively included all consecutive patients, from January 2015 through February 2016, who received an intravenous amikacin loading dose for suspected Gram-negative infection in a context of venoarterial (VA) or venovenous (VV) ECMO in our ICU. Only the first dose of amikacin was studied. Four types of ECMO systems with poly-4-methyl-1-pentene membrane oxygenators (PLS system, Cardiohelp system, both Maquet, Rastatt, Germany; Hilite 7000 LT system, Medos, Stolberg, Germany; ECC.05 system, Sorin, Mirandola, Italy) were used during the study period. Exclusion criteria were (1) incorrect amikacin regimen ( $<23$ or $>27 \mathrm{mg} / \mathrm{kg}$ TBW); (2) incorrect time of amikacin infusion ( $\pm 5 \mathrm{~min})$; or $(3)$ incorrect time $( \pm 5 \mathrm{~min})$ or absence of $\mathrm{C}_{\max }$ determination. Patients with incorrect time of trough serum concentration $\left(C_{\min }\right)$ determination $( \pm 1 \mathrm{~h})$ were not excluded if $\mathrm{C}_{\max }$ had been obtained correctly.

\section{Amikacin administration and serum-concentration dosage} Amikacin was administered according to our ICU's written standardized protocol: $25 \mathrm{mg} / \mathrm{kg}$ TBW (weighing bed weight of the day), diluted in $50 \mathrm{~mL}$ of $0.9 \% \mathrm{NaCl}$ and continuously infused over $30 \mathrm{~min}$. When the patient's weight was $>120 \mathrm{~kg}$, a maximum of $120 \mathrm{~kg}$ was considered to calculate the loading amikacin dose (five patients in our study). $C_{\max }$ was assessed $30 \mathrm{~min}$ after that infusion ended and $\mathrm{C}_{\min } 24 \mathrm{~h}$ after the latter. Our Microbiology Laboratory used a fluorescence-polarization immunoassay to determine amikacin concentrations, as a routine procedure available $24 \mathrm{~h}$ /day, 7 days/week [13].

\section{Data collection}

Demographic data, Simplified Acute Physiology Score (SAPS) II [14], and reason for ECMO were collected for all patients. ECMO-membrane duration was defined as the delay between membrane first use and the time of amikacin infusion. Organ dysfunction at inclusion (i.e. the day of amikacin administration) was assessed with the Sequential Organ-Failure Assessment (SOFA) score. In addition, laboratory tests, including coagulation parameters, complete blood count, electrolytes, liver enzymes, urea, creatinine, and bilirubin, were run. At inclusion, the inotrope score was calculated [15], defined as:

Dobutamine dose $(\gamma / \mathrm{kg} / \mathrm{min})+[$ Norepinephrine dose $(\gamma / \mathrm{kg} / \mathrm{min})+$ Epinephrine dose $(\gamma / \mathrm{kg} / \mathrm{min})] \times 100$.

The 24-h fluid balance was defined as the difference between fluid intake and fluid output over the $24 \mathrm{~h}$ 
before amikacin infusion. Proteinemia and hematocrit changes during the $24 \mathrm{~h}$ preceding inclusion were calculated as follows:

$\left(\mathrm{X}_{0 \mathrm{~h}}-\mathrm{X}_{24 \mathrm{~h}}\right) /\left(\mathrm{X}_{0 \mathrm{~h}}+\mathrm{X}_{24 \mathrm{~h}}\right) / 2$.

In addition, renal function was characterized according to the Kidney Disease: Improving Global Outcomes (KDIGO) classification [16]. Acute renal failure in ICU survivors was defined as KDIGO $\geq 2$. Lastly, infection sites and identified pathogens were noted.

\section{Statistical analyses}

Categorical variables are expressed as number (percentage) and compared using the chi-square test. Continuous variables are expressed as medians (1st; 3 rd quartile) and compared using Student's $t$ test or Wilcoxon's signed-rank test. Pre-amikacin infusion factors associated with a $C_{\max }<60 \mathrm{mg} / \mathrm{L}$ or a $C_{\max }>80 \mathrm{mg} / \mathrm{L}$ were selected using univariable mixed models. Demographics and clinical and biological factors with a $p$ value $\leq 0.10$ in our univariable analyses were entered into the multivariable mixed model. The list of data entered in both models is provided in Additional file 1: Table S1. Few relevant variables with a plausible clinical link despite a value of $p>0.10$ in the univariate analysis were forced into the models (Additional file 1: Table S1). Continuous variables were transformed into categorical variables (the optimal thresholds were defined by analyzing mortality in each corresponding variable quartile). Thereafter, multiple backward-stepwise logistic-regression analyses eliminated variables with an exit threshold set at $p>$ 0.05 . All potential explanatory variables included in the multivariable analyses were subjected to collinearity analysis with a correlation matrix. In the case of collinearity between factors, the most clinically relevant factor was chosen to construct the multivariable model. Results are reported as odds ratios (ORs) and their 95\% confidence intervals (CIs).

Given the observed $\mathrm{C}_{\max }$ and the administered dose/ kilogram, we assumed amikacin PK linearity [17-20] to simulate individual $\mathrm{C}_{\max }$ for the following dosing regimen: $20 \mathrm{mg} / \mathrm{kg}, 25 \mathrm{mg} / \mathrm{kg}, 30 \mathrm{mg} / \mathrm{kg}, 35 \mathrm{mg} / \mathrm{kg}$ TBW. In order to provide dosing regimen recommendations, for each dosing regimen, we estimated the probability of $\mathrm{C}_{\max }$ in the therapeutic range $(60-80 \mathrm{mg} / \mathrm{L})$ for the different categories of the risk factors found predictive of under-dosing in the multivariable analysis.

Analyses were computed using StatView v5.0 (SAS Institute, Cary, NC, USA), SPSS v22.0 software (SPSS, Chicago, IL, USA) and R v3.3.0 (http://www.R-project.org).

\section{Results}

\section{Study population}

During the study period, among 302 ECMO-treated patients in our ICU, 119 (39\%) received an amikacin loading dose for severe sepsis or septic shock; 13 were excluded from our analysis for the main reasons listed in Fig. 1. Consequently, PK of a first amikacin loading dose on ECMO were studied in 106 patients. Patient characteristics at ICU admission and study inclusion are shown in Table 1 . Median (IQR) age was $55(45 ; 62)$ years, while median SAPS II was 68 (47; 81). VA-ECMO supported $68 \%$ of the patients. On the day of amikacin infusion, the SOFA score was $15(12 ; 18)$ with $54(51 \%)$ patients on renal replacement therapy. The main infection sites were lung and cannula for, respectively, 77\% and $14 \%$ patients, with associated bacteremia in 15 (17\%); the most frequently identified pathogens were P. aeruginosa, Enterobacter spp. and Escherichia coli (Additional file 1: Table S2).

\section{Pharmacokinetic parameters}

Amikacin PK parameters are reported in Table 2. The median ECMO cannulation-to- $C_{\max }$ interval was 9 (5; 15) days. After receiving a loading dose of $25(24 ; 25.5)$ $\mathrm{mg} / \mathrm{kg}$ TBW, median $\mathrm{C}_{\max }$ was $65.8(51.8 ; 82.4) \mathrm{mg} / \mathrm{L}$. $\mathrm{C}_{\max }$ was $<60 \mathrm{mg} / \mathrm{L}$ in 41 patients $(39 \%)$ and $>80 \mathrm{mg} / \mathrm{L}$ in 27 (25\%) (Additional file 1: Figure S1). Median $\mathrm{C}_{\text {min }}$ for 85 patients was $7.25(3.6 ; 13.6) \mathrm{mg} / \mathrm{L}$, with only 24 patients $(28 \%)$ having a value $<2.5 \mathrm{mg} / \mathrm{L}$.

\section{Factors predictive of $C_{\max }<60 \mathrm{mg} / \mathrm{L}$}

Univariable analyses selected lower body mass index (BMI), higher liver-enzyme concentrations, lower proteinemia, lower hematocrit and positive 24-h fluid balance as factors predictive of $\mathrm{C}_{\max }<60 \mathrm{mg} / \mathrm{L}$ (Table 1).

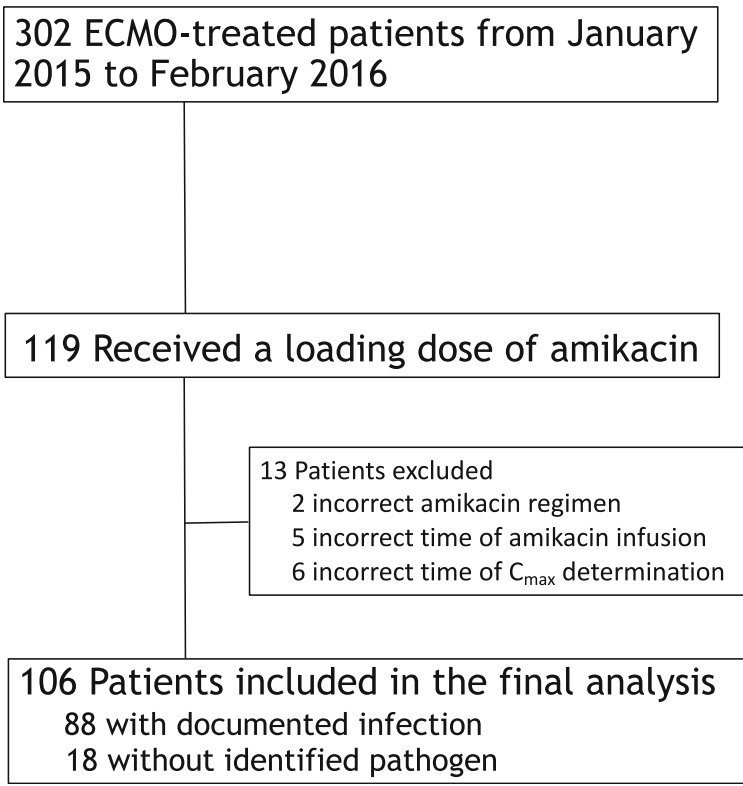

Fig. 1 Study flow chart. ECMO, extracorporeal membrane oxygenation; $C_{\text {max }}$, peak serum concentration 
Table 1 Total population characteristics and univariable analyses of factors predictive of amikacin $C_{\max }<60 \mathrm{mg} / \mathrm{L}$

\begin{tabular}{|c|c|c|c|c|}
\hline Characteristic & Total population $(n=106)$ & $C_{\max }<60 \mathrm{mg} / \mathrm{L}(n=41)$ & $C_{\max } \geq 60 \mathrm{mg} / \mathrm{L}(n=65)$ & $p$ \\
\hline \multicolumn{5}{|l|}{ At ICU admission } \\
\hline Age, years & $55(44-62)^{a}$ & $54(39-64)$ & $57(48-60)$ & 0.61 \\
\hline Male & $77(73)$ & $28(68)$ & $49(75)$ & 0.42 \\
\hline SAPS $\|$ & $68(47 ; 81)$ & $70(46 ; 81)$ & $68(47 ; 81)$ & 0.66 \\
\hline $\mathrm{BMI}, \mathrm{kg} / \mathrm{m}^{2}$ & $26(23 ; 31)$ & $25(22 ; 29)$ & $26(24 ; 33)$ & 0.03 \\
\hline \multicolumn{5}{|l|}{ At inclusion } \\
\hline SOFA score & $15(12 ; 18)$ & $16(13 ; 18)$ & $14(11 ; 18)$ & 0.12 \\
\hline Weight, kg & $80(71 ; 97)$ & $79(65 ; 91)$ & $80(73 ; 98)$ & 0.24 \\
\hline Height, m & $1.72(1.65-1.78)$ & $1.70(1.65-1.75)$ & $1.75(1.68-1.78)$ & 0.18 \\
\hline ICU admission-to-ECMO interval, days & $1(0 ; 7)$ & $1(0 ; 5)$ & $1(0 ; 8)$ & 0.52 \\
\hline ICU admission-to- $C_{\max }$ interval, days & $9(5 ; 15)$ & $8(3 ; 15)$ & $9(6 ; 15)$ & 0.46 \\
\hline ECMO-to- $C_{\max }$ interval, days & $6(3 ; 11)$ & $7(1 ; 12)$ & $6(3 ; 9)$ & 0.99 \\
\hline Inotrope score, $\mu \mathrm{g} / \mathrm{kg} / \mathrm{min}$ & $30(5 ; 131)$ & $68(10 ; 150)$ & $21(5 ; 105)$ & 0.12 \\
\hline Reason for ECMO & & & & 0.68 \\
\hline Cardiogenic shock & $49(46)$ & $17(41)$ & $32(49)$ & \\
\hline Post-cardiac transplant & $9(8)$ & $3(7)$ & $6(9)$ & \\
\hline Cardiac arrest & $7(7)$ & $2(5)$ & $5(8)$ & \\
\hline Post-cardiotomy & $6(6)$ & $2(5)$ & $4(6)$ & \\
\hline Severe ARDS & $35(33)$ & $17(41)$ & $18(28)$ & \\
\hline VA-ECMO & $72(68)$ & $25(61)$ & $47(72)$ & 0.22 \\
\hline ECMO flow, L/min & $4.0(3.0 ; 5.0)$ & $4.2(3.2 ; 5.4)$ & $3.7(2.9 ; 4.6)$ & 0.13 \\
\hline Weight-indexed ECMO flow, L/min/kg & $0.49(0.37-0.58)$ & $0.53(0.42-0.64)$ & $0.46(0.36-0.55)$ & 0.013 \\
\hline ECMO-membrane duration, days & $5(2 ; 8)$ & $4(1 ; 8)$ & $5(3 ; 8)$ & 0.16 \\
\hline \multicolumn{5}{|l|}{ Laboratory finding } \\
\hline Aspartate aminotransferase, $\mathrm{mmol} / \mathrm{L}$ & $79(41 ; 267)$ & $99(44 ; 747)$ & $71(39 ; 188)$ & 0.08 \\
\hline Alanine aminotransferase, $\mathrm{mmol} / \mathrm{L}$ & $56(27 ; 157)$ & $69(41 ; 377)$ & $53(25 ; 126)$ & 0.08 \\
\hline Bilirubin, $\mathrm{mmol} / \mathrm{L}$ & $27(16 ; 67)$ & $23(17 ; 66)$ & $30(15 ; 67)$ & 0.92 \\
\hline Prothrombin time, $\%$ & $65(51 ; 77)$ & $62(43 ; 76)$ & $66(54 ; 78)$ & 0.16 \\
\hline$\vee$ factor, $\%$ & $75(47 ; 112)$ & $59(29 ; 107)$ & $83(57 ; 123)$ & 0.08 \\
\hline Proteinemia, g/L & $53(43 ; 58)$ & $49(44 ; 55)$ & $55(48 ; 59)$ & 0.02 \\
\hline Albuminemia, g/L & $21(19 ; 25)$ & $22(19 ; 25)$ & $21(19 ; 25)$ & 0.86 \\
\hline Prealbuminemia, $g / L$ & $0.13(0.09 ; 0.19)$ & $0.13(0.11 ; 0.19)$ & $0.13(0.09 ; 0.19)$ & 0.65 \\
\hline Hematocrit, \% & $25(23 ; 27)$ & $24(22 ; 27)$ & $25(23 ; 29)$ & 0.09 \\
\hline Lactates, mmol/L & $1.8(1.2 ; 4.0)$ & $1.9(1.1 ; 6.3)$ & $1.8(1.3 ; 3.8)$ & 0.89 \\
\hline \multicolumn{5}{|l|}{ Hemodilution parameter } \\
\hline 24-h fluid balance, $\mathrm{mL}$ & $225(-980 ; 1607)$ & $1000(200 ; 2045)$ & $-371(-1564 ; 1342)$ & $<0.001$ \\
\hline 24-h protidemia delta, $\%$ & $0(-5 ; 3.5)$ & $0(-5.6 ; 1.8)$ & $0(-3.9 ; 5.0)$ & 0.37 \\
\hline 24-h hematocrit delta, \% & $0.0(-5.2 ; 3.5)$ & $0.0(-5.6 ; 1.8)$ & $0.0(-3.9 ; 5.0)$ & 0.38 \\
\hline $\mathrm{GFR}, \mathrm{mL} / \mathrm{min}$ & $2(0 ; 69)$ & $0(0 ; 84)$ & $6(0 ; 61)$ & 0.97 \\
\hline Renal function & & & & 0.42 \\
\hline KDIGO-0 & $30(28)$ & $14(34)$ & $16(25)$ & \\
\hline KDIGO-1 & $11(10)$ & $2(5)$ & $9(14)$ & \\
\hline KDIGO-2 & $6(6)$ & $2(5)$ & $4(6)$ & \\
\hline KDIGO-3 & $59(56)$ & $23(56)$ & $36(55)$ & \\
\hline
\end{tabular}


Table 1 Total population characteristics and univariable analyses of factors predictive of amikacin $C_{\max }<60$ mg/L (Continued)

\begin{tabular}{|c|c|c|c|c|}
\hline Characteristic & Total population $(n=106)$ & $\mathrm{C}_{\max }<60 \mathrm{mg} / \mathrm{L}(n=41)$ & $C_{\max } \geq 60 \mathrm{mg} / \mathrm{L}(n=65)$ & $p$ \\
\hline $\mathrm{KDIGO} \geq 2$ & $65(61)$ & $25(61)$ & $40(62)$ & 0.95 \\
\hline Dialysis & $9(8)$ & $1(2)$ & $8(12)$ & 0.07 \\
\hline CRRT & $45(42)$ & $22(54)$ & $23(35)$ & 0.06 \\
\hline \multicolumn{5}{|l|}{ Outcome } \\
\hline ICU mortality & $57(54)$ & $21(51)$ & $36(55)$ & 0.67 \\
\hline Hospital mortality & $58(55)$ & $21(51)$ & $37(57)$ & 0.57 \\
\hline ECMO duration, days & $18(10 ; 26)$ & $18(8.5 ; 24.5)$ & $18(10 ; 27)$ & 0.83 \\
\hline Mechanical ventilation duration, days & $22(12 ; 41)$ & $26(17 ; 46)$ & $20(12 ; 38)$ & 0.32 \\
\hline RRT duration after $C_{\text {max }}$, days & $15(5 ; 24)$ & $15(4 ; 26)$ & $14(5 ; 21)$ & 0.64 \\
\hline $\mathrm{AKI}^{\mathrm{b}}$ at ICU discharge in survivors ${ }^{c}$ & $11(23)$ & $5 / 20(12)$ & $6 / 29(9)$ & 0.65 \\
\hline
\end{tabular}

$A K I$ acute kidney injury, $A R D S$ acute respiratory distress syndrome, $B M I$ body mass index, $C_{\text {max }}$ peak serum concentration $C R R T$ continuous renal replacement therapy, GFR glomerular filtration rate, ICU intensive care unit, KDIGO Kidney Disease: Improving Global Outcomes, SAPS Simplified Acute Physiology Score, SOFA Sequential Organ-Failure Assessment, VA-ECMO venoarterial extracorporeal membrane oxygenation

aValues are expressed as median (1st; 3rd quartile) or number (percentage)

${ }^{\mathrm{b}}$ Defined as KDIGO $\geq 2$

'Based on 49 ICU survivors

Multivariable analyses retained $\mathrm{BMI}<22 \mathrm{~kg} / \mathrm{m}^{2}(\mathrm{OR}$, 6.38; 95\% CI, 1.79-22.77; $p=0.043$ ) and 24-h fluid balance (OR per $500-\mathrm{mL}$ increment, 1.28 ; 95\% CI, 1.05$1.65 ; p=0.041)$ as being independently associated with a higher risk of $\mathrm{C}_{\max }<60 \mathrm{mg} / \mathrm{L}$. A linear relationship between the probability of amikacin $\mathrm{C}_{\max }<60 \mathrm{mg} / \mathrm{L}$ and 24-h fluid balance was observed. That probability reached $>60 \%$ when 24-h fluid balance exceeded $2000 \mathrm{~mL}$ (Fig. 2). Notably, we did not find any significant association between $\mathrm{C}_{\max }<60 \mathrm{mg} / \mathrm{L}$ and ECMO settings (i.e. VA or $\mathrm{VV})$, ECMO flow, and ECMO membrane duration.

Factors predictive of $\mathrm{C}_{\max }>\mathbf{8 0} \mathrm{mg} / \mathrm{L}$

Univariable analyses selected higher BMI, ECMO flow, dialysis, and higher hematocrit as factors predictive of $\mathrm{C}_{\max }>80 \mathrm{mg} / \mathrm{L}$ (Additional file 1: Table S3): 24-h-hour

Table 2 Pharmacokinetic/pharmacodynamic parameters at inclusion in 106 patients

\begin{tabular}{ll}
\hline Variable & Value $^{\mathrm{a}}$ \\
\hline Weight at time of $C_{\text {max }}, \mathrm{kg}$ & $80.0(71.0 ; 97.5)$ \\
Amikacin dose, $\mathrm{mg}$ & $2000(1750 ; 2500)$ \\
Amikacin regimen, $\mathrm{mg} / \mathrm{kg}$ & $25.0(24.0 ; 25.5)$ \\
Amikacin $C_{\max } \mathrm{mg} / \mathrm{L}$ & $65.8(51.8 ; 82.4)$ \\
Patients with $C_{\max }<60 \mathrm{mg} / \mathrm{L}$ & $41(39)$ \\
Patients with $C_{\max }>80 \mathrm{mg} / \mathrm{L}$ & $27(25)$ \\
ICU admission-to- $C_{\min }$ interval, h & $24.1(23.4 ; 24.8)$ \\
Amikacin $C_{\min ,} \mathrm{mg} / \mathrm{L}$ & $7.25(3.60 ; 13.60)$ \\
Patients with $C_{\min }<2.5 \mathrm{mg} / \mathrm{L}^{\mathrm{b}}$ & $24(28)$ \\
\hline$C_{\max }$ &
\end{tabular}

$C_{\max }$ peak serum concentration, $C_{\min }$ trough serum concentration avalues are expressed as median (1st; 3rd quartile]) or number (percentage)

${ }^{\mathrm{b}}$ Available for 85 patients fluid balance was forced into the logistic regression (Additional file 1: Table S1). Multivariable analyses retained only higher BMI (OR, 1.10; 95\% CI, 1.03-1.18; $p=0.0037)$ as being independently associated with a higher risk of $\mathrm{C}_{\max }>80 \mathrm{mg} / \mathrm{L}$.

\section{Dosing simulations}

Figure 3 describes the simulated $\mathrm{C}_{\max }$ for various amikacin dosing regimens in a critically ill patient on ECMO with either a 24-h positive or negative fluid balance and a BMI $<$ or $\geq 22 \mathrm{~kg} / \mathrm{m}^{2}$. The probability of target attainment $\left(C_{\max } 60-80 \mathrm{mg} / \mathrm{L}\right)$, under-dosing $\left(C_{\max }<60 \mathrm{mg} /\right.$ $\mathrm{L})$ and overdosing $\left(\mathrm{C}_{\max }>80 \mathrm{mg} / \mathrm{L}\right)$ is also reported. These data show that increasing amikacin doses up to $30 \mathrm{mg} / \mathrm{kg}$ for patient with a positive $24 \mathrm{~h}$-fluid balance may increase the likelihood of reducing under-dosing. Based on dosing simulation, $28 \%$ of these patients still exhibit under-dosing with $30 \mathrm{mg} / \mathrm{kg}$, whereas it will also expose the patient to more frequent overdosing (Fig. 3). In addition, increasing amikacin dosing regimen up to $30 \mathrm{mg} / \mathrm{kg}$ and $35 \mathrm{mg} / \mathrm{kg}$ TBW when 24-h fluid balance is positive and the BMI is $\geq 22 \mathrm{~kg} / \mathrm{m}^{2}$ or $<22 \mathrm{~kg} / \mathrm{m}^{2}$ (Table 3 ), respectively, would have potentially led to the therapeutic target being reached in $42 \%$ of patients while reducing under-dosing incidence to $23 \%$ of patients (Additional file 1: Figure S2).

\section{Outcomes}

Overall in-ICU mortality was 54\% after, respectively, 22 $(12 ; 41)$ days on mechanical ventilation and $18(10 ; 26)$ days on ECMO. Among ICU survivors, the 11 patients (23\%) who suffered acute kidney injury (AKI) had comparable $C_{\max }$ levels to those without AKI (Table 2). No 


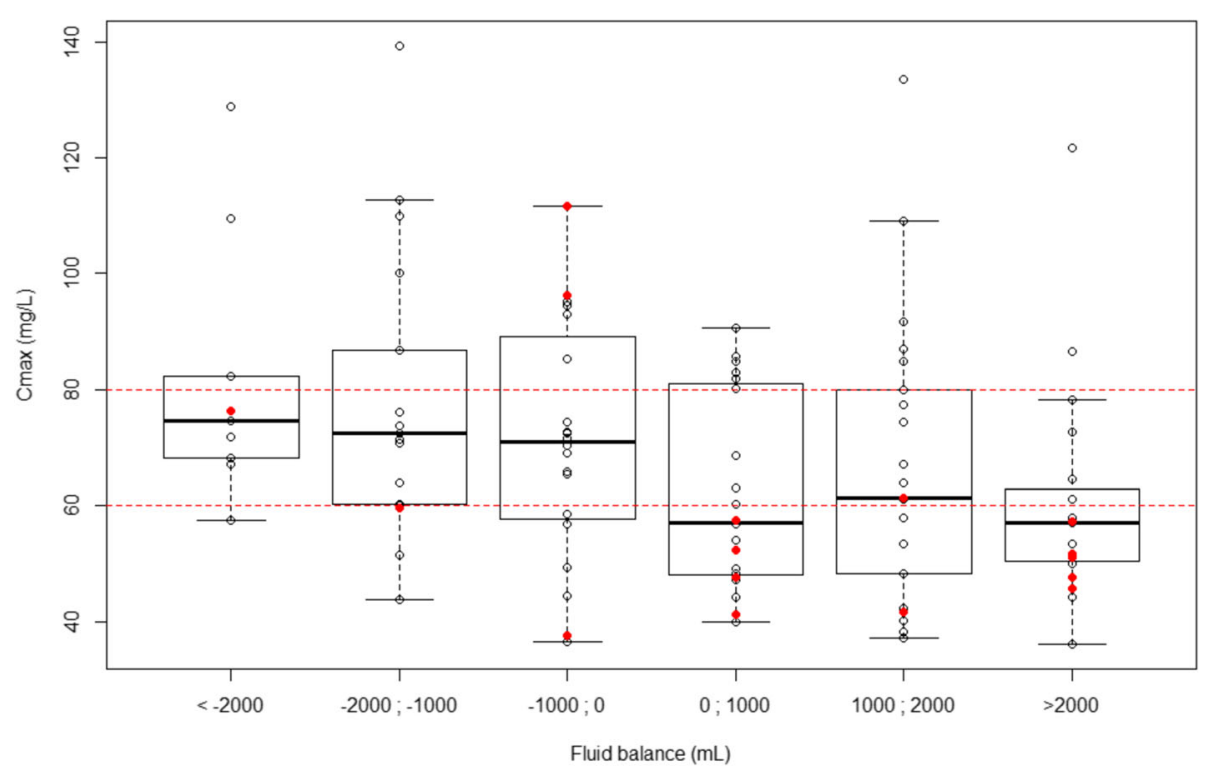

Fig. 2 Amikacin peak serum concentration ( $C_{\text {max }}$ ) after a single dose of $25 \mathrm{mg} / \mathrm{kg}$ total body weight according to 24-h fluid balance on extracorporeal membrane oxygenation (ECMO). Concentrations in patients with body mass index (BMI) $<22 \mathrm{~kg} / \mathrm{m}^{2}$ or $>22 \mathrm{~kg} / \mathrm{m}^{2}$ are represented by red dots and circles, respectively. Boxplots represent the distribution of the concentrations. The lower and upper borders correspond to the first and third quartiles. The upper whisker extends from the borders to the highest value that is within $1.5 *$ interquartile range (IQR) of the borders, or the distance between the first and third quartiles. The lower whisker extends from the borders to the lowest value within $1.5 *$ IQR of the hinge. Red dashed lines represent the therapeutic margin (60-80 $\mathrm{mg} / \mathrm{L})$

association was found between ICU mortality and insufficient $C_{\max }$ or too high $C_{\text {min }}$. In addition, ICU mortality did not differ significantly in patients with $\mathrm{C}_{\max }<60$, $60-80$, or $>80 \mathrm{mg} / \mathrm{L}(59 \%, 52 \%$, or $51 \%$, respectively).

\section{Discussion}

The results of our large prospective study indicate that amikacin under-dosing on ECMO after a loading dose of $25 \mathrm{mg} / \mathrm{kg}$ TBW is frequent, with more than a third of the patients having $C_{\max }<60 \mathrm{mg} / \mathrm{L}$. In addition, using a $25 \mathrm{mg} / \mathrm{kg}$ amikacin dosing regimen led to $64 \%$ of patients with a $\mathrm{C}_{\max }$ outside the targeted range of $60-80 \mathrm{mg} / \mathrm{L}$. Independent risk factors for amikacin under-dosing were $\mathrm{BMI}<22 \mathrm{~kg} / \mathrm{m}^{2}$ and positive $24-\mathrm{h}$ fluid balance, in agreement with previous studies without ECMO [17-20]. No association between under-dosing or overdosing of amikacin and outcome was found. Last, dosing simulations might suggest to increase the amikacin dosing regimen up to $30 \mathrm{mg} / \mathrm{kg}$ and $35 \mathrm{mg} / \mathrm{kg}$ TBW when $24-\mathrm{h}$ fluid balance is positive and the BMI is $>22 \mathrm{~kg} / \mathrm{m}^{2}$ or the BMI is $<22 \mathrm{~kg} / \mathrm{m}^{2}$, respectively.

Describing antibiotic PK in the population on ECMO is essential to understand whether special dosing may be required. Unfortunately, such data on ECMO-treated adults are sparse and the available literature is mainly restricted to ex-vivo studies $[4,6,21]$. Systemic inflammatory responses, organ dysfunction, drug interactions and organ support are all known to affect antibiotic PK in critically ill patients. Drug PK seems to be more markedly modified on ECMO [6]. General PK parameters of hydrophilic antibiotics, like aminoglycosides, are low $\mathrm{Vd}$, predominantly with renal clearance, and low intracellular penetration [22].

Recently, in a large case series of 146 severely ill patients receiving 181 amikacin infusions, including $15 \%$ on ECMO, $\mathrm{C}_{\max }$ was $<60 \mathrm{mg} / \mathrm{L}$ during $33 \%$ of the episodes. Independent risk factors were $\mathrm{BMI}<25 \mathrm{~kg} / \mathrm{m}^{2}$ and positive 24-h fluid balance [11]. Although many factors, e.g. the extracorporeal circuit, high-volume fluid infusion and the extreme severity of critical illness in the patients could contribute to a larger Vd on ECMO, we found similar frequencies of amikacin under-dosing and overdosing with the same risk factors. Based on a smaller cohort of 46 ECMO-treated patients, Gelisse et al. reported a similar percentage of $C_{\max }$ insufficiency, when matched with critically ill patients without ECMO support [5]. We postulate that, as demonstrated without ECMO [19-21], the intensity of interstitial fluid shift during sepsis on ECMO will result in a larger $\mathrm{Vd}$, which might lower plasma antibiotic concentrations. It is worth noting that the increased $\mathrm{Vd}$ in septic patients may be attributed to hypoalbuminemia and the resulting decreased oncotic pressure [22], which was low in our population.

Low BMI (i.e. $<22 \mathrm{~kg} / \mathrm{m}^{2}$ ) was the second independent risk factor for $C_{\max }<60 \mathrm{mg} / \mathrm{L}$, which agrees with published observations $[11,12]$. With hydrophilic drugs, like 

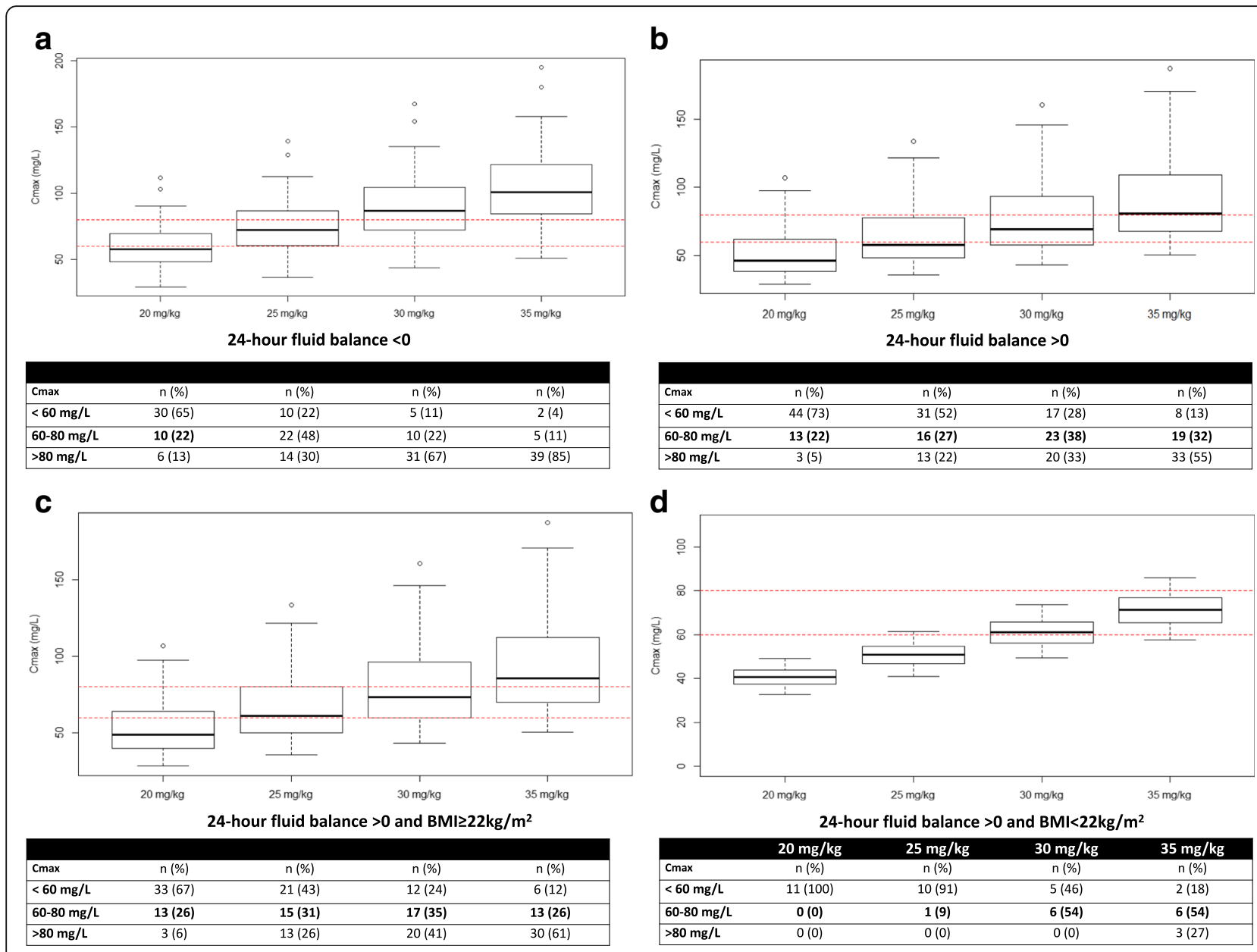

d

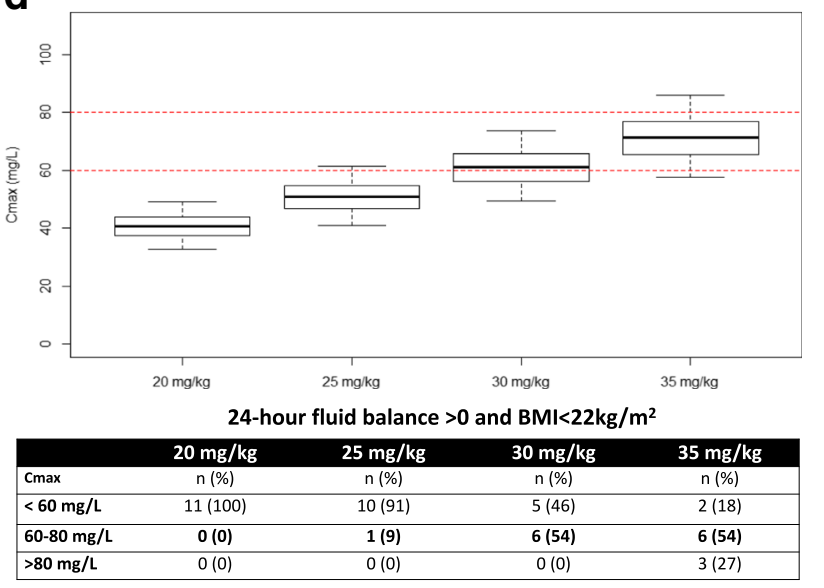

Fig. 3 Simulated peak serum concentration $\left(C_{\max }\right)$ and probability of amikacin efficacy, under-dosing, and overdosing for various dosing regimens in a critically ill patient on extracorporeal membrane oxygenation (ECMO) with a negative 24-h fluid balance (a); a positive 24-h fluid balance (b); a positive $24-\mathrm{h}$ fluid balance and body mass index (BMI) $\geq 22 \mathrm{~kg} / \mathrm{m}^{2}$ (c); or a positive $24-\mathrm{h}$ fluid balance and BMl $<22 \mathrm{~kg} / \mathrm{m}^{2}$ (d)

amikacin, using TBW for dose calculation in high-BMI patients, instead of ideal body weight or adjusted body weight, could overestimate amikacin Vd. Indeed, higher BMI was the only factor that was independently associated with a higher risk of overdosing in our study. Surprisingly, although, a poor TBW-Vd relationship has been thoroughly described, the amikacin loading dose is still commonly adjusted to TBW. Therefore, we cannot rule out the fact that using adjusted body weight in obese patients [23] would have led to different findings.

Notably, Allou et al. [24] and Galvez et al. [25] reported, without a clear explanation, that amikacin overexposure (i.e. $\mathrm{C}_{\max }>80 \mathrm{mg} / \mathrm{L}$ ) might potentially be

Table 3 Proposal for amikacin dosing regimens on ECMO according to 24-h fluid balance and body mass index (BMI)

\begin{tabular}{lll}
\hline & $\mathrm{BMl}<22 \mathrm{~kg} / \mathrm{m}^{2}$ & $\mathrm{BMl} \geq 22 \mathrm{~kg} / \mathrm{m}^{2}$ \\
\hline Negative 24-h fluid balance & $25 \mathrm{mg} / \mathrm{kg}$ & $25 \mathrm{mg} / \mathrm{kg}$ \\
Positive 24-h fluid balance & $35 \mathrm{mg} / \mathrm{kg}^{\mathrm{a}}$ & $30 \mathrm{mg} / \mathrm{kg}$ \\
\hline
\end{tabular}

${ }^{\mathrm{a}}$ Based on only 11 patients with these characteristics associated with increased mortality. Although, our study was not designed to analyze mortality, we did not observe any $C_{\max }-$ mortality association. Moreover, an amikacin $\mathrm{C}_{\min }>2.5 \mathrm{mg} / \mathrm{L}$ was not significantly associated with a higher AKI rate at ICU discharge. Considering the high amikacin under-dosing frequency in our ECMO-treated patients and our dosing simulations, our dosing simulation suggests that increasing the loading dose up to a $35 \mathrm{mg} / \mathrm{kg}$ TBW dose for low-BMI patients and those with positive 24-h fluid balance on ECMO could help to obtain adequate target concentrations. However, these dosing simulations deserve to be confirmed by future prospective studies or Monte-Carlo-based simulations. Less frequent under-dosing has also been reported without a higher AKI rate, using a higher loading dose [24, 26]. However, despite the current trend toward increasing antibiotic doses in ICUs, no beneficial effect on outcome has been clearly demonstrated. In addition, it can be argued that a lower amikacin $\mathrm{C}_{\max }$ might be enough to obtain $\mathrm{C}_{\max } / \mathrm{MIC}>8$ 
for most isolated strains that often have amikacin MICs $\leq$ $4 \mathrm{mg} / \mathrm{L}$ [26].

Our study's strengths include the large cohort investigated, focusing on the impact of ECMO, its longitudinal design and a short interval retained for the correct time of $\mathrm{C}_{\max }$ determination. However, it also has limitations. First, it is a single-center study in an ICU with a high volume of ECMO cases in a tertiary-care university hospital, and our results may not be generalizable to all ICUs. Second, our ECMO population was a mix of patients who received VA-ECMO and VV-ECMO support, with different outcomes and underlying illnesses. Given that the underlying diseases of these extremely ill patients is key in antibiotic PK modifications on ECMO, our results might have been different if we had focused on a subpopulation of patients on ECMO (i.e. those with cardiac or respiratory failure). However, our multivariable analysis did not identify reasons for ECMO and type of ECMO hook-up as factors predictive of $\mathrm{C}_{\max }$ $<60 \mathrm{mg} / \mathrm{L}$. Third, we cannot exclude that coadministration with another antibiotic and other ICU treatments might also have contributed to AKI at ICU discharge. Fourth, our dosing simulation was based on amikacin PK linearity [17-20] and a limited number of patients $(n=11)$ with positive 24-h fluid balance and $\mathrm{BMI}<22 \mathrm{~kg} / \mathrm{m}^{2}$. And finally, we cannot rule out that a portion of amikacin might have been sequestrated on the ECMO membrane, as previously described on the hemofilter membrane [27].

\section{Conclusions}

Despite an amikacin loading dose of $25 \mathrm{mg} / \mathrm{kg}$ TBW in the ECMO-treated patients included in our large prospective study, we found that more than a third of them did not reach the targeted $C_{\max }>60 \mathrm{mg} / \mathrm{L}$. Increasing the dose to $35 \mathrm{mg} /$ $\mathrm{kg}$ in low-BMI patients and those with positive 24-h fluid balance on ECMO to reach adequate targeted concentrations should be investigated. However, the impact of a higher amikacin loading dose on AKI frequency and outcomes remains unclear. Further human PK studies are urgently needed to confirm our results and develop population PK models to provide dosing guidelines for patients on ECMO.

\section{Additional file}

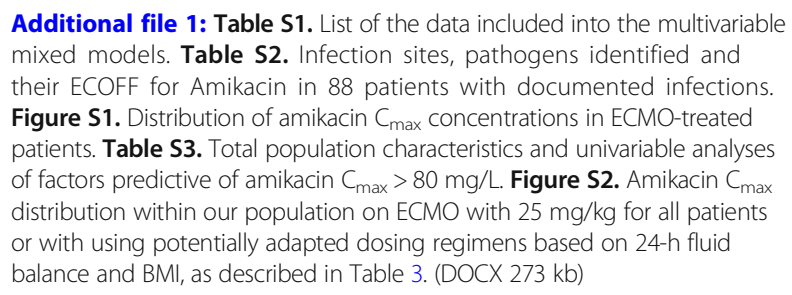
mixed models. Table S2. Infection sites, pathogens identified and their ECOFF for Amikacin in 88 patients with documented infections. Figure S1. Distribution of amikacin $C_{\max }$ concentrations in ECMO-treated patients. Table S3. Total population characteristics and univariable analyses of factors predictive of amikacin $C_{\max }>80 \mathrm{mg} / \mathrm{L}$. Figure S2. Amikacin $C_{\max }$ distribution within our population on ECMO with $25 \mathrm{mg} / \mathrm{kg}$ for all patients or with using potentially adapted dosing regimens based on 24-h fluid balance and BMI, as described in Table 3. (DOCX $273 \mathrm{~kb}$ )

\section{Abbreviations}

AKl: Acute kidney injury; ARDS: Acute respiratory distress syndrome; BMI: Body mass index; $C_{\text {max }}$ : Peak serum concentration; $C_{\text {min }}$ : Trough serum concentration; ECMO: Extracorporeal membrane oxygenation; ICU: Intensive care unit; KDIGO: Kidney Disease: Improving Global Outcomes; MIC: Minimal inhibitory concentration; OR: Odds ratio; PK: Pharmacokinetics; SAPS: Simplified Acute Physiology Score; SOFA: Sequential Organ-Failure Assessment; TBW: Total body weight; VA-ECMO: Venoarterial extracorporeal membrane oxygenation;

Vd: Volumes of distribution

\section{Availability of data and materials}

The datasets used and/or analyzed during the current study are available from the corresponding author on reasonable request.

\section{Authors' contributions}

$\mathrm{C}, \mathrm{NB}, \mathrm{GF}, \mathrm{GH}, \mathrm{GL}, \mathrm{SB}, \mathrm{AN}$, and MS analyzed and interpreted the patient data. AA performed the pharmacodynamic analysis. PE performed pharmacokinetics simulations. CT, MS, PL, CEL, and AC were major contributors in writing the manuscript. All authors read and approved the final manuscript.

\section{Ethics approval and consent to participate}

The study protocol was in accordance with the ethical standards of our hospital's Institutional Review Board (Committee for the Protection of Human Subjects). In accordance with French law, informed consent was not obtained for demographic, physiological and hospital-outcome data analyses because this observational study did not modify existing diagnostic or therapeutic strategies. However, patients and/ or relatives were informed about the anonymous data collection and that they could decline inclusion. This database was registered at the Commission Nationale I'Informatique et des Libertés (CNIL, registration number 1950673).

\section{Consent for publication}

In accordance with French law, informed consent was not obtained for demographic, physiological and hospital-outcome data analyses because this observational study did not modify existing diagnostic or therapeutic strategies. However, patients and/or relatives were informed about the anonymous data collection and that they could decline inclusion.

\section{Competing interests}

Alain Combes has received lecture fees from Baxter and Gettinge and is the primary investigator of the EOLIA trial (NCT01470703), partly supported by Maquet-Gettinge. Matthieu Schmidt has received lectures fees from Gettinge and Dräger. The remaining authors have no conflicts of interest.

\section{Publisher's Note}

Springer Nature remains neutral with regard to jurisdictional claims in published maps and institutional affiliations.

\section{Author details}

${ }^{1}$ Medical Intensive Care Unit, iCAN, Institute of Cardiometabolism and Nutrition, Hôpital de la Pitié-Salpêtrière, Assistance Publique-Hôpitaux de Paris, Sorbonne University , Paris 6, 47, bd de l'Hôpital, 75651 Paris Cedex 13, France. ${ }^{2}$ Laboratory of Microbiology, Hôpital de la Pitié-Salpêtrière, Assistance Publique-Hôpitaux de Paris, Sorbonne University , Paris 6, 47, bd de l'Hôpital, 75651 Paris Cedex 13, France. ${ }^{3}$ Department of Epidemiology, Biostatistics and Clinical Research, Bichat Hospital, AP-HP, F-75018 Paris, France. ${ }^{4}$ Cardiac Surgery Department, iCAN, Institute of Cardiometabolism and Nutrition, Hôpital de la Pitié-Salpêtrière, Assistance Publique-Hôpitaux de Paris, Sorbonne University , Paris 6, 47, bd de l'Hôpital, 75651 Paris Cedex 13, France.

Received: 17 January 2018 Accepted: 9 July 2018 Published online: 19 August 2018

\section{References}

1. Karagiannidis C, Brodie D, Strassmann S, Stoelben E, Philipp A, Bein T, et al. Extracorporeal membrane oxygenation: evolving epidemiology and mortality. Intensive Care Med. 2016;42:889-96.

2. Schmidt M, Brechot N, Hariri S, Guiguet M, Luyt CE, Makri R, et al. Nosocomial infections in adult cardiogenic shock patients supported by venoarterial extracorporeal membrane oxygenation. Clin Infect Dis. 2012;55:1633-41. 
3. Belohlavek J, Springer D, Mlcek M, Huptych M, Boucek T, Hodkova G, et al. Early vancomycin, amikacin and gentamicin concentrations in pulmonary artery and pulmonary tissue are not affected by VA ECMO (venoarterial extracorporeal membrane oxygenation) in a pig model of prolonged cardiac arrest. Pulm Pharmacol Ther. 2013;26:655-60.

4. Shekar K, Roberts JA, McDonald Cl, Ghassabian S, Anstey C, Wallis SC, et al. Protein-bound drugs are prone to sequestration in the extracorporeal membrane oxygenation circuit: results from an ex vivo study. Crit Care. 2015;19:164

5. Gelisse E, Neuville M, de Montmollin E, Bouadma L, Mourvillier B, Timsit JF, et al. Extracorporeal membrane oxygenation (ECMO) does not impact on amikacin pharmacokinetics: a case-control study. Intensive Care Med. 2016; 42:946-8.

6. Shekar K, Roberts JA, McDonald Cl, Fisquet S, Barnett AG, Mullany DV, et al. Sequestration of drugs in the circuit may lead to therapeutic failure during extracorporeal membrane oxygenation. Crit Care. 2012;16:R194.

7. Micek ST, Welch EC, Khan J, Pervez M, Doherty JA, Reichley RM, et al. Empiric combination antibiotic therapy is associated with improved outcome against sepsis due to gram-negative bacteria: a retrospective analysis. Antimicrob Agents Chemother. 2010;54:1742-8.

8. European Committee on Antimicrobial Susceptibility testing (EUCAST). www.eucast.org/clinical_breakpoints/. Accessed 1 June 2018.

9. Moore RD, Lietman PS, Smith CR. Clinical response to aminoglycoside therapy: importance of the ratio of peak concentration to minimal inhibitory concentration. J Infect Dis. 1987;155:93-9.

10. (2011) A. Bon usage des aminosides administre' s par voie injectable: gentamicine, tobramycine, netilmicine, amikacine-mise au point. [Internet]. 2017. Available from: http://ansm.sante.fr/Mediatheque/ Publications/ Recommandations- Medicaments.

11. de Montmollin E, Bouadma L, Gault N, Mourvillier B, Mariotte E, Chemam S, et al. Predictors of insufficient amikacin peak concentration in critically ill patients receiving a $25 \mathrm{mg} / \mathrm{kg}$ total body weight regimen. Intensive Care Med. 2014;40:998-1005.

12. Taccone FS, Laterre PF, Spapen H, Dugernier T, Delattre I, Layeux B, et al. Revisiting the loading dose of amikacin for patients with severe sepsis and septic shock. Crit Care. 2010;14:R53.

13. Blaser J, Konig C, Fatio R, Follath F, Cometta A, Glauser M. Multicenter quality control study of amikacin assay for monitoring once-daily dosing regimens. Int Antimicrobial Ther Coop Group of the Eur Organ Res Treat Cancer Ther Drug Monit. 1995;17:133-6.

14. Le Gall JR, Lemeshow S, Saulnier F. A new simplified acute physiology score (SAPS II) based on a European/North American multicenter study. JAMA 1993;270:2957-63.

15. Brechot $N$, Luyt CE, Schmidt M, Leprince $P$, Trouillet $J$, Leger $P$, et al. Venoarterial extracorporeal membrane oxygenation support for refractory cardiovascular dysfunction during severe bacterial septic shock. Crit Care Med. 2013:41:1616-26.

16. Ketteler M, Block GA, Evenepoel P, Fukagawa M, Herzog CA, McCann L, et al. Executive summary of the 2017 KDIGO chronic kidney disease-mineral and bone disorder (CKD-MBD) guideline update: what's changed and why it matters. Kidney Int. 2017;92:26-36.

17. Burdet C, Pajot O, Couffignal C, Armand-Lefevre L, Foucrier A, Laouenan C, et al. Population pharmacokinetics of single-dose amikacin in critically ill patients with suspected ventilator-associated pneumonia. Eur J Clin Pharmacol. 2015;71:75-83.

18. Delattre IK, Musuamba FT, Nyberg J, Taccone FS, Laterre P-F, Verbeeck RK, et al. Population pharmacokinetic modeling and optimal sampling strategy for Bayesian estimation of amikacin exposure in critically ill septic patients. Ther Drug Monit. 2010;32:749-56.

19. Lugo G, Castañeda-Hernández G. Relationship between hemodynamic and vital support measures and pharmacokinetic variability of amikacin in critically ill patients with sepsis. Crit Care Med. 1997;25:806-11.

20. Romano S, Del Mar Fdez de Gatta M, Calvo V, Mendez E, Dominguez-Gil A, Lanao JM. Influence of clinical diagnosis in the population pharmacokinetics of amikacin in intensive care unit patients. Clin Drug Investig. 1998;15:435-44.

21. Lemaitre F, Luyt CE, Roullet-Renoleau F, Nieszkowska A, Zahr N, Fernandez $C$, et al. Oseltamivir carboxylate accumulation in a patient treated by haemodiafiltration and extracorporeal membrane oxygenation. Intensive Care Med. 2010;36:1273-4.
22. Jamal JA, Economou CJ, Lipman J, Roberts JA. Improving antibiotic dosing in special situations in the ICU: burns, renal replacement therapy and extracorporeal membrane oxygenation. Curr Opin Crit Care. 2012;18:460-71.

23. Pai MP, Bearden DT. Antimicrobial dosing considerations in obese adult patients. Pharmacotherapy. 2007;27:1081-91.

24. Allou N, Bouteau A, Allyn J, Snauwaert A, Valance D, Jabot J, et al. Impact of a high loading dose of amikacin in patients with severe sepsis or septic shock. Ann Intensive Care. 2016;6:106.

25. Galvez R, Luengo C, Cornejo R, Kosche J, Romero C, Tobar E, et al. Higher than recommended amikacin loading doses achieve pharmacokinetic targets without associated toxicity. Int J Antimicrob Agents. 2011;38:146-51.

26. Roger C, Nucci B, Louart B, Friggeri A, Knani H, Evrard A, et al. Impact of 30 $\mathrm{mg} / \mathrm{kg}$ amikacin and $8 \mathrm{mg} / \mathrm{kg}$ gentamicin on serum concentrations in critically ill patients with severe sepsis. J Antimicrob Chemother. 2016;71:208-12.

27. Tian Q, Gomersall CD, Ip M, Tan PE, Joynt GM, Choi GYS. Adsorption of amikacin, a significant mechanism of elimination by hemofiltration. Antimicrob Agents Chemother. 2008;52:1009-13.

\section{Ready to submit your research? Choose BMC and benefit from:}

- fast, convenient online submission

- thorough peer review by experienced researchers in your field

- rapid publication on acceptance

- support for research data, including large and complex data types

- gold Open Access which fosters wider collaboration and increased citations

- maximum visibility for your research: over $100 \mathrm{M}$ website views per year

At $\mathrm{BMC}$, research is always in progress.

Learn more biomedcentral.com/submissions 